\title{
FAKE NEWS: \\ O QUE SÃO E COMO INTER(AGEM) NA ERA DA PÓS-VERDADE
}

\author{
Francisco Jeimes de Oliveira Paiva* \\ Eduardo Dias da Silva
}

RESUMO: A pós-verdade tornou-se algo condicionante na eleição presidencial de 2018 no Brasil, travou-se nesse evento uma verdadeira guerra híbrida, ideológica e discursiva em torno do poder político, econômico e cultural. Por isso, as informações foram conduzidas estrategicamente a fim de fomentar a discórdia entre a elite hegemônica detentora do capital financeiro e político e os grupos com representação política minoritária que apesar de serem numerosos são hoje os mais afetados pelas decisões governamentais e políticas de cunho conservador, ultraliberal, autoritário e entreguista. Dessa forma, neste artigo, descrevo e analiso à luz da análise de discurso crítica a constituição multimodal e ideológica do discurso político da direita conservadora, reacionária e elitista brasileira em prol da campanha presidencial de Jair Messias Bolsonaro, materializado na reprodução de algumas Fake news compartilhadas nas páginas Brasil Verde e Amarelo e Brasil, teu povo acordou. A análise multimodal crítica depreendida evidenciou que o objetivo das Fake news, replicadas no facebook, foram (des)informar e manipular os/as eleitores/as, seguidores/as, enfim, a população que teve acesso a esses discursos marcados pela pós-verdade sobre o possível perigo do retorno de um governo de esquerda capaz de subverter os valores patrióticos, conservadores, ultraliberais e cristãos da família brasileira.

PALAVRAS-CHAVE: Fake news. Discurso Político. Materialidade Discursiva. Multimodalidade.

\footnotetext{
* Mestre em História e Letras na Faculdade de Educação, Ciências e Letras do Sertão Central (FECLESC) da Universidade Estadual do Ceará (Uece).

** Doutorando em Litearatura e Mestre em Linguística Aplicada pela Universidade de Brasília (UnB). Pesquisador nos Grupos CNPq FORPROLL e GIEL.
} 


\section{Fake news: o que são e como elas inter(agem) na sociedade em rede - conectando algumas questões iniciais}

E, no entanto, somos forçados, se buscamos o eterno e imutável, a tentar e deixar a nossa marca no caótico, no efêmero e no fragmentário.

David Harvey (2012, p. 26).

Atualmente, pensar nas atividades humanas na cultura digital, nos faz refletir criticamente como se constituem e como inter(agem) multimodalmente os discursos políticos veiculados por meio da elaboração e compartilhamento de Fake news (notícias falsas) em grupos políticos nas redes sociais em tempos de pós-verdade ${ }^{1}$. Trago, a princípio, a definição de Fake news, elaborada pela Rede de Jornalismo Ético, considerando-as como “[...] informações deliberadamente fabricadas e publicadas com a intenção de enganar e induzir os outros a crer em falsidades ou duvidar de fatos verificáveis" (WHITE, 2017, minha tradu$(\tilde{a} 0)^{2}$.

Sabe-se que [a]s redes sociais digitais são os instrumentos mais céleres e eficazes de comunicação e veiculação de informação que a internet disponibilizou aos seus usuários" (TEIXEIRA et al., 2018, p. 1). Pode-se dizer que as Fake news se apresentam como conteúdos sensacionalistas e que apelam para a emoção dos/as leitores/as devido ao seu poder viral de espalhar-se de forma rápida, conseguindo atingir um determinado grupo ou público, sobretudo, nas redes sociais.

Por isso, o Facebook, Instagram, Twitter, Snapchat, dentre outros, têm conquistado enorme espaço na sociedade em razão da sua importância como mídia social digital alternativa em relação aos grandes veículos de comunicação tradicionais e impressos, tornando acessível uma diversidade de textos verbo-visuais, discursos e conteúdos a muitos grupos,

\footnotetext{
${ }^{1}$ Segundo Carvalho e Mateus (2018, p. 6), o conceito de pós-verdade é baseado na banalização da verdade, ou seja, dados objetivos são ignorados, e o apelo na formação da opinião junto ao público fala mais alto que a veracidade dos fatos, criando uma confusão sobre a realidade [...]. Daí se torna uma arma tão igual ou mais poderosa que as Fake News, pois apela para um discurso emotivo populista.

${ }^{2}$ WHITE, Aidan. Fake News: It's Not Bad Journalism, it's the Business of Digital Communications. 2 mai. 2017. Disponível em: https://ethicaljournalismnetwork.org/fake-news-bad-journalism-digital-age. Acesso em: 22 abr. 2019.
} 
usuários e pessoas mesmo que não estejam em si comprometidos com a verdade, a ética e a democratização do acesso aos bens culturais digitais, enfim, a informação.

De certo, vivemos visivelmente uma guerra híbrida, ideológica e discursiva, escamoteada por lutas pela hegemonia do discurso e pelo poder instituído politicamente. Logo, é crucial analisar que a corrida presidencial no Brasil em 2018, o segundo turno, nos apresentou de um lado, um candidato sem experiência alguma em administração pública, além de ser ultraliberal, misógino, racista e defensor de um projeto de poder que favoreceu a elite branca, capitalista e militar, e de outro tínhamos no páreo um professor universitário com vasta experiência de gestão governamental, que representa um governo ligado a um projeto social e de democratização ao acesso à educação superior, emprego e renda, casa popular, remédios a baixo custo, enfim, que pauta-se pela transparência administrativa e pela promoção de políticas públicas voltadas aos grupos que se encontram em desvantagem social no Brasil.

Segundo Ramalho e Maia (2018, p. 188), essa guerra adveio da atuação nas redes sociais digitais e pautada nas ações pelo ativismo social "representa a apreensão de um contexto social, cultural, tecnológico e político permeado pela massificação das tecnologias da informação e comunicação (TICs)". Isso se dá justamente pelo fenômeno da midiatização (GOMES, 2015; HAJVARD, 2014; SODRÉ, 2013), o que permitiu, na visão desses autores, a denominada liberação do polo emissor e recepção da informação ${ }^{3}$ e a elevação de uma gama desmesurada de produtores/as e consumidores/as de conteúdo que, sobretudo por meio da internet e dos dispositivos técnicos a ela atrelados (tais como smartphones, computadores, tablets etc.), fazendo valer suas opiniões, comentários e ideias sobre determinados

\footnotetext{
${ }^{3}$ Gomes (2016, p. 16) evidencia que a circulação de mensagens acontece de forma imediata entre o polo da emissão e o polo da recepção. O mesmo processo acontece midiaticamente. A mídia se apropria de conteúdos e os trabalha por meio dos processos de significação e socioculturais. Esse movimento complexo acontece dentro dos contextos dos processos midiáticos. A circulação também se estrutura em conexões e interconexões que se desenrolam no marco das relações que a sociedade engendra para que a comunicação aconteça com rapidez e eficácia. Os conteúdos transmitidos chegam à sociedade e seus resultados retornam para o processo de comunicação, via processos midiáticos, gerando, assim, um ambiente comunicacional mais amplo que influencia e é influenciado pelos seres humanos.
} 
temas da vida cotidiana, logo essas práticas sociais/discursivas são ideologicamente situadas pelo contexto social e pela necessidade de comunicação cada vez mais multimodal, ou seja, via mídias sociais.

Além do mais, é visível que as mídias sociais mudaram socialmente a natureza dos grupos e as relações de poder ao possibilitar que os indivíduos se associem e se organizem diretamente a partir de interesses comuns e compartilhados, em um sistema de flexibilidade estrutural e através de fluxos de comunicação rápida e simultâneo, fazendo delas não apenas veículos/meios, mas, principalmente, espaços de produção de saberes e conhecimentos diversos (GEE, 2009).

Recuero (2017) ao analisar redes sociais online salienta que

[a] ideia que embasa os estudos das estruturas sociais é aquela de que os indivíduos, os atores sociais, estão inseridos em estruturas complexas de relações com outros atores. Essas estruturas têm um papel fundamental no comportamento e na visão de mundo desses indivíduos, mais do que outras categorias muitas vezes tomadas a priori como mais importantes, como classe social, sexo ou idade (DEGENNE; FORSÉ, 1999; WASSERMAN; FAUST, 1994 apud RECUERO, 2017, p. 8).

Nessa perspectiva, pode-se notar que existe a necessidade de uma convergência para a Análise de Redes Sociais (ARS), que é segundo Recuero (2017, p. 8), uma das vertentes de estudo de grupos sociais que permitem sua análise sistemática a partir de sua estrutura, por meio de instrumentos específicos para esta. Ademais, considerando que os cenários digitais trouxeram à tona múltiplas interações humanas na web de forma diversificada aos estudiosos da linguagem (ARAÚJO; LEFFA, 2016).

Pata tanto, acredito que o esforço interpretativo do analista e a sua capacidade de relacionar texto e contexto com base nas perspectivas teóricas interdisciplinares implicadas, foram fundamentais para que a análise dessa dimensão da complexidade discursiva e narrativa percebida no contexto das redes sociais digitais (RAMALHO; MAIA, 2018, p. 197).

Conectando, enfim, os/as leitores/as a esta discussão, procuro descrever e analisar na perspectiva da Análise de Discurso Crítica (FAICLOUGH, 2001; VAN DIJK, 2010, 
2016), a constituição multimodal e ideológica do discurso político da direita conservadora, reacionária e elitista brasileira em prol da campanha presidencial de Jair Messias Bolsonaro, materializado na reprodução de algumas Fake news na página Brasil Verde e Amarelo4 e Brasil, teu povo acordou5, veiculados no período eleitoral no facebook.

\section{Analisando a materialidade do discurso político das Fake news em postagens no} facebook dos grupos - Brasil verde e amarelo e Brasil, teu povo acordou

Considerando que não se pode teórico-metodologicamente reduzir a ADC apenas como se fosse uma técnica universalista de pesquisa, visto que a "ACD é um modo de investigação crítica, onde teoria e metodologia estão intrinsecamente inter-relacionadas” (CHOULIARAKI; FAIRCLOUGH, 2010, p. 1215), passamos, em um primeiro momento, na visão faircloughiana dialética-relacional, a entender o discurso como modo de ação que estabelece mudanças sociais e nos diferentes discursos expõe também uma forma de consumo por parte dos receptores e na "função identitária relaciona-se aos modos pelos quais as identidades sociais são estabelecidas no discurso" (FAIRCLOUGH, 2001, p. 92).

Mais adiante, dimensiono também que o discurso político em um viés inter e multidisciplinar e sociocognitivo pode ser visto como uma atitude da prática analítica de pesquisadores/as que se voltam para entender, explicar, expor e "finalmente, desafiar a desigualdade social" (VAN DIJK, 2016, p. 19), procurando demonstrar como o abuso de poder e a desigualdade são reproduzidos e legitimados nos grupos sociais que se encontram em desvantagem. O autor elucida que "o abuso de poder vai se manifestar na língua onde existe a variação ou escolha, dependendo da posição ou da ideologia do falante" (VAN DIJK, 2010, p. 13). Por isso, concordamos que

${ }^{4}$ Disponível em: https://www.facebook.com/Brasil-Verde-e-Amarelo-292878371326201/. Acesso em: 22 abr. 2019.

${ }^{5}$ Disponível em: https://www.facebook.com/brasilverdeeamarelo/. Acesso em: 22 abr. 2019. 
O discurso como prática política estabelece, mantém e transforma as relações de poder e as entidades coletivas (classes, blocos, comunidades, grupos) entre as relações de poder. $\mathrm{O}$ discurso como ideológica constitui, naturaliza, mantém e transforma os significados do mundo de posições diversas nas relações de poder (FAIRCLOUGH, 2001, p. 94).

Considerando-se a materialidade do discurso como ideológico, porque segundo Wodak (2004) o discurso vai muito além da linguagem por envolver aspectos ideológicos e relações de poder, sendo que a ideologia é capaz de manter ou criar outras as relações desiguais de poder.

Neste artigo, partilho da ideia de que os textos como artefatos culturais e repletos de ideologias requerem uma análise que leve em conta à sua produção, distribuição e consumo, com atenção especial aos fatores de coerência textual, à presença da força ilocucionária, além do próprio processo acional que a linguagem desempenha através dos enunciados, discursos, textos e aos graus de intertextualidade e interdiscursividade (FAIRCLOUGH, 2001, 2003), isto é, essas práticas discursivas são corporificadas por meio das atividades sociocognitivas que os atores sociais exercem no bojo de suas interações (MELO, 2011).

Observe as construções multimodais do discurso de pós-verdade nas páginas iniciais que apresentam os grupos:

Brasil Verde e Amarelo e Brasil, teu povo acordou, a fim de enunciar confiabilidade em seus usuários sobre as informações ali veiculadas, buscando convencê-los/as que o candidato deles/as é a cara do Brasil que queremos (patriótico, verde e amarelo que representa a valorização da nação brasileira, dos valores e da família brasileira etc.).

Percebe-se, então, uma dualidade de cores, materializando as ideologias ${ }^{6}$, postas de cada grupo, de um lado o verde e amarelo, enaltecendo a brasilidade e o patriotismo e de

\footnotetext{
${ }^{6}$ A ideologia, para Thompson (2011), é uma forma de controle social, pela qual construímos e mantemos relações de poder na sociedade. Por isso, estudar a ideologia é pensar nas maneiras como o sentido serve, em circunstâncias específicas, para estabelecer e sustentar essas relações de poder e, portanto, muitas vezes, de dominação (TOMAZI; EFFGEN; SESSA, 2017, p. 191).
} 
outro as cores avermelhadas do ideário petista, distorcida pelos bolsonaristas ao longo das narrativas das fake como pessoas violentas, diabólicas, anticristãs e corruptas.

Figura 1 - Foto de página inicial do grupo "Brasil Verde e Amarelo"

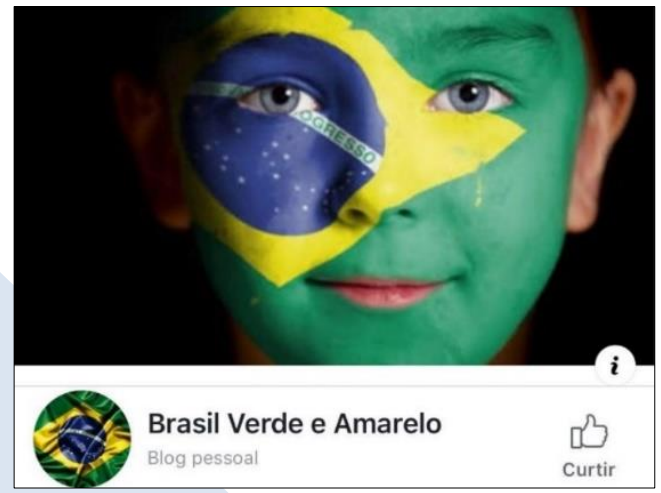

Fonte:https://www.facebook.com/292878371326201/photos/ a.292879277992777/292879261326112/?type=1\&theater. Acesso em: 20 abr. 2019.

Na figura 2, fica evidente o bordão de campanha de Bolsonaro: "Brasil acima de tudo, Deus acima de todos”, segundo a Gazeta do Povo (2018)7 foi uma apropriação de brado da Brigada de Infantaria Paraquedista do Exército. O candidato foi paraquedista em sua trajetória militar, assim como o seu vice, o general da reserva Hamilton Mourão (PRTB). Se bem que para Casali, essa construção foi muito questionada em virtude à semelhança com o brado nazista de "Alemanha acima de tudo" (no alemão, "Deutschland über alles”). Sabe-se que esse bordão foi a máxima ideológica usada pelo candidato a fim de incutir na mente dos/as eleitores/as uma personificação de candidato honesto, patriota e cristão para atender os diversos públicos, sobretudo nacionalistas, ultraliberais, cristãos, por exemplo.

${ }^{7}$ Disponível em: https://www.gazetadopovo.com.br/politica/republica/eleicoes-2018/brasil-acima-de-tudo-conheca-a-origem-do-slogan-de-bolsonaro-7r6utek3uk1axzyruk1fj9nas/. Acesso em: 20 abr. 2019. 
Figura 2 - Foto de página inicial do grupo "Brasil, teu povo acordou"

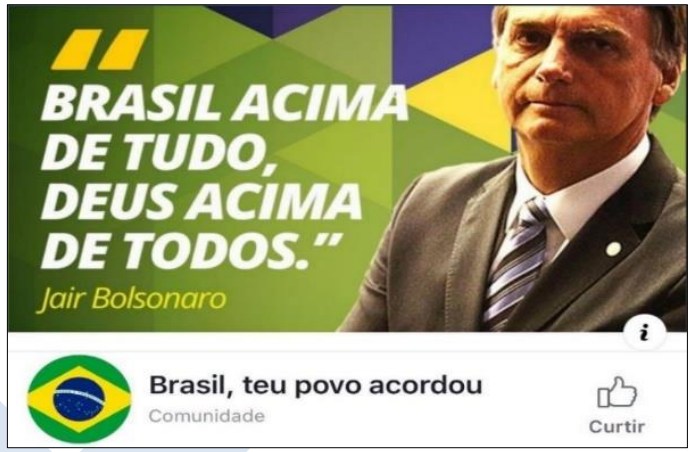

Fonte:https://www.facebook.com/brasilverdeeamarelo/photos/p.794217530954168/794217530954168/?type=1\&theater. Acesso em: 20 abr. 2019.

Na figura 2, tanto o bordão "Brasil acima de tudo, Deus acima de todos" quanto o nome do grupo bolsonarista "Brasil, teu povo acordou" resvalam discursos políticos recorrentes na campanha e na disseminação das Fake news como instrumento de manipulação dos/as eleitores/as, porque os/as atores sociais são constituídos a partir de seus modelos mentais pessoais que sistematizam suas crenças/ideologias, sobre determinada causa. O entendimento desses discursos dependerá de um "complexo processo de decodificação e compreensão" do que está sendo explicitado e pela construção dos modelos mentais subjetivos (experiências diárias, conhecimento) de quem recebe o discurso (TOMAZI; EFFGEN; SESSA, 2017, p. 129).

As práticas discursivas dos atores bolsonaristas na cultura digital, se efetivam, ao se alastrar as Fake news corporificadas por atividades do midiativismo ${ }^{8}$ em que o discurso de pós-verdade se materializou pela mescla intertextual de fatos verificáveis com intenções maliciosas, apenas objetivando angariar votos para se ganhar o pleito, fazendo uso de vários

\footnotetext{
${ }^{8}$ Peruzzo (2018, p. 43) enfatiza que "o termo midiativismo (media ativism) aponta para um fenômeno social de múltiplas perspectivas, cujos "atores" são tanto do âmbito dos movimentos sociais e organizações não governamentais, quanto de grupos independentes, coletivos e cidadãos/cidadãs que desenvolvem ativismo mediático por meio de meios de comunicação, dentro deles e sobre eles".
} 
recursos semióticos e discursivos pelo uso de vídeos, fotos, imagens, fatos etc., ligados aos adversários, partidos e ideologias contrárias ao que se defende na plataforma política de seu candidato.

Observe a seguir alguns exemplos, disponíveis no grupo Brasil, teu povo acordou: Figura 3 - vídeo com notícias falsas sobre o PT Figura 4 - vídeo sobre microcefalia
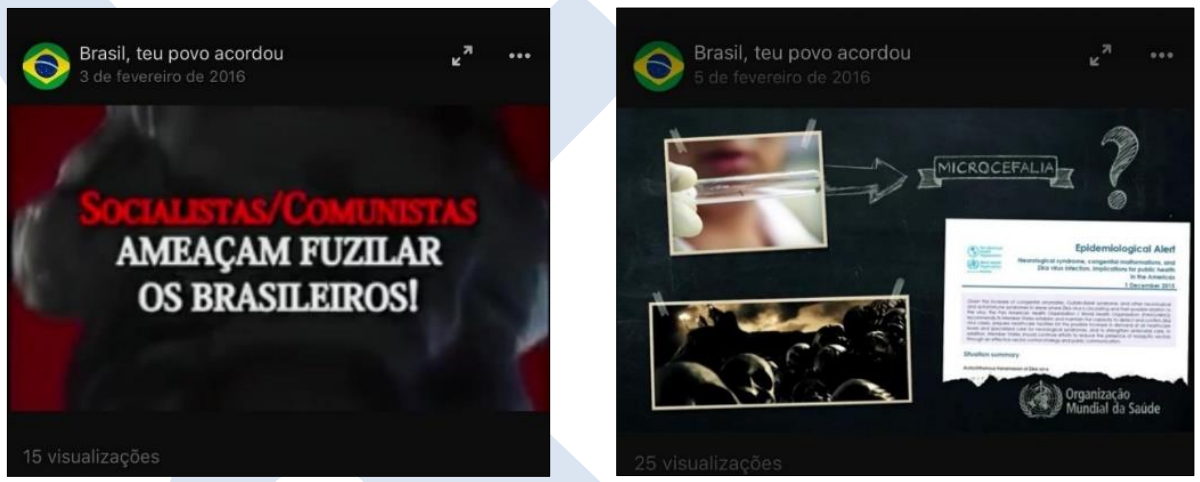

Fonte: https://www.facebook.com/brasilverdeeamarelo/videos/164156667293594/. Acesso em: 23 abr. 2019.

Tanto as figuras 3 e 4, tratam-se de notícias falsas produzidas possivelmente por participantes/administradores do grupo, com o fim de “demonizar” o adversário político Fernando Haddad pelo Partido dos Trabalhadores, durante a campanha o próprio candidato e seus seguidores falam em uma ditadura comunista/socialista no Brasil que foi contida graças à ação dos militares, sobretudo em 1964.

Ou seja, a estratégia ideológica para legitimar os ataques aos adversários políticos se materializa em discurso de ódio/ violência verbal, mas também espalhando mentiras, demonizando o PT e seus seguidores, além de naturalizar o discurso de que as epidemias, doenças no Brasil a fora são culpa deste, do governo da presidente Dilma Rousseff. 
No primeiro vídeo, os bolsonaristas exploram e distorcem uma fala de um dos fundadores do PT, Sérgio Paladini ${ }^{9}$, procurando depreciar a imagem de Haddad, dizendo que este partido desejar "fuzilar" os fascistas, logo os/as bolsonaristas assumem o fato como verdadeiro e reagem de forma viral de forma violenta com falas racistas, preconceituosas contra os nordestinos, mulheres, pobres como já é de praxe durante as eleições e após o pleito. No segundo vídeo, os bolsonaristas propagam a ideia de que a causa da microcefalia ${ }^{10}$ no Brasil seria uma praga enviada contra os desmandos e corrupções ligadas ao partido adversário.

Sob essa perspectiva, as relações de poder, segundo Fairclough (2001) conduzem a um movimento de discursos para as práticas sociais, percebe-se que os Fake news deste estudo, apresentam um discurso de momento, um diálogo exposto a ponderações ideológicas e surgido a partir de intenções maliciosas de confundir/enganar os/as eleitores/as. Constata-se, do ponto de intersecção entre as práticas sociais e os textos, as práticas discursivas não são apenas um lugar de construção de ideologias, mas, de maneira especial, de sua (des)construção, um espaço potencial de transformação das relações de dominação e de poder instituídos (PEIXOTO, 2014).

Observe a seguir alguns exemplos, disponíveis no grupo Brasil Verde e Amarelo:

Figura 5 - vídeo sobre gastos dos Jogos Olimpicos

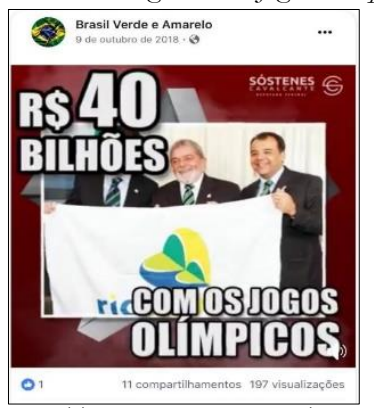

Figura 6 - vídeo de fala de Haddad

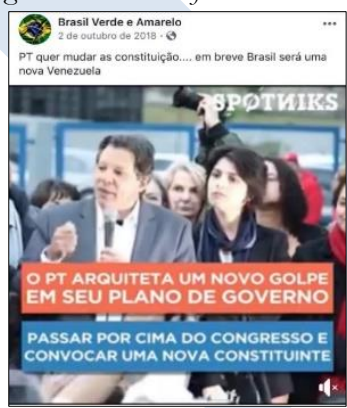

Fonte: https://www.facebook.com/292878371326201/videos/1910925869022852/. Acesso em: 23 abr. 2019.

9 Disponível em: https://www.youtube.com/watch?v=WsVvZpI6nas\&feature=youtu.be\&fbclid=IwAR1Y4 LBD4zQ6A8wNWeH-DInHLXZWg3PD9nKi_VZl8kbuA_dHq4cU5nXFte0. Acesso em: 23 abr. 2019. ${ }^{10}$ https://www.facebook.com/brasilverdeeamarelo/videos/164156667293594/. Acesso em: 23 abr. 2019. 
No caso, estas Fake news foram massivamente compartilhadas nas eleições com o objetivo de consolidar um discurso de anticorrupção bolsonarista, primeiro contra o PT como um todo, ao atingir a pessoa mais influente e mais populista, o Lula, falseando dados sobre seu governo, sobretudo, indicando superfaturamento nas obras da Copa e dos Jogos Olímpicos, no vídeo se enaltece a estrutura "Como sobrevivemos ao PT?", no sentido de convencer os/as usuários de quem este partido não representa a dignidade, as bandeiras nacionais contra a corrupção, discurso presente na Lava-Jato do juiz Sérgio Moro.

Consequentemente, a visão bolsonarista era a de que seria preciso "varrer" do comando do país, os políticos de esquerda. Inclusive, na figura 5 e 6 exemplificam esse discurso de demonizar politicamente a ideologia de esquerda contra o republicanismo brasileiro, uma vez que eles propagaram e fabricaram notícias falsas, enfatizando uma possível ditadura de esquerda no Brasil e que era preciso um candidato honesto, republicado, condizente com os valores da família cristã para os salvarem de uma ditadura comunista e corrupta, mancomunada com o que há de pior no país.

De forma viral, os/as bolsonaristas dos dois grupos ainda ativos no facebook, buscaram sem medir esforços atingir a campanha de Fernando Haddad por meio do uso massivo de Fake news, reforçando a necessidade de um candidato messiânico, capaz de extirpar do Brasil uma ditatura petista/comunista que corroía, na visão da plataforma política bolsonarista, os valores familiares e cristãos brasileiros.

Constatou-se ainda pela análise crítica dos conteúdos, áudios, imagens, cores, discursos etc., que houve, sem dúvida, um verdadeiro controle dos contextos, sistemas e estruturas dos textos, das falas ou da escrita como forma de exercitar o poder e, ao mesmo tempo, controlar a mente das pessoas pelo discurso, influenciando suas crenças e fortalecendo a dominância e a hegemonia (TOMAZI; EFFGEN; SESSA, 2017, p. 129).

A despeito disso, Van Djik acentua que "um estudo do discurso político é teórica e empiricamente relevante apenas quando as estruturas discursivas podem ser relacionadas a propriedades das estruturas e processos políticos" (VAN DIJK, 2012, p.197-198). Logo, a análise crítica das Fake news materializadas em práticas sociais nas eleições de 2018, nos 
forneceu subsídios para compreensão das ideologias embutidas nos discursos políticos da direita ultraconservadora brasileira.

Em suma, ficou evidente que os dois grupos bolsonaristas exerceram o poder do uso de notícias falsas para manipular e ganhar votos. Por isso, Van Dijk (2012), diz que o abuso de poder por um grupo social, ocorre por meio da dominação e funciona por processos sociocognitivos, porque estar relacionado à manipulação das mentes dos indivíduos na sociedade.

\section{Considerações finais}

O que é Fake news para um fanático é verdade cristalina para o fanático da seita oposta. Otavio Frias Filho (2018, p. 42).

A análise multimodal crítica das Fake news replicadas no facebook, objetivou a (des)informação e a manipulação dos/as eleitores/as, seguidores/as, visando atingir com um discurso de pós-verdade a população sobre o possível perigo do retorno de um governo de esquerda capaz de subverter os valores patrióticos, conservadores, ultraliberais e cristãos da família brasileira, defendidos a todo instante pelo candidato Jair Bolsonaro, mesmo que de forma violenta, racista e preconceituosa as ideias bolsonaristas visam utilizar-se de discursos anticorrupção e antipetista com fim de ganhar o pleito eleitoral.

Evidentemente, os compartilhamentos, comentários e a forma viral nas redes sociais com que as Fake news analisadas se materializaram no pensar/agir, nos dá indícios de que os/as usuários não possuem critérios para verificar os fatos espalhados em rede, uma vez que os grupos Brasil, teu povo acordon e Brasil Verde e Amarelo já operavam no sentido de convencer os receptadores/a de que essas informações falsas são fatos concretos, logo nessa guerra híbrida, cultural e ideológica tais estratégias políticas foram necessárias para salvar o Brasil de uma ditatura comunista/socialista e anticristã.

Constatou-se que o uso dessas Fake news contribuiu negativamente na qualidade da informação, pois o poder de interdição dos atores sociais por meio da força de persuasão, 
da dominação, hegemonia e da ideologia (MELO, 2011), foi massificado e corporificado por estes dois grupos bolsonaristas. Dessa forma, a análise e a discussão feita neste artigo, nos permitiu compreender que as estruturas sociais e as atividades humanas nas redes sociais, no facebook, revelaram que os discursos foram reconstruídos no ciberespaço, sobretudo, nas estruturas de dominação da sociedade (RECUERO, 2016).

Apesar de poucos estudos sobre o fenômeno midiático e do midiativismo ${ }^{11}$ das Fake news através das variadas e das configurações complexas (PERUZZO, 2018) das atividades de seus atores (e actantes) nas redes sociais, sobretudo na área da Linguística Aplicada e Análise de Discurso.

Esta pesquisa, portanto, comprovou a manipulação constante do eleitorado em aderir/acreditar (em sua estrutura mental) o discurso misógino, racista, antipetista propagado durante a campanha por Jair Bolsonaro e seus seguidores nas mídias de comunicação alternativa através da fabricação de vídeos, fotos e textos mal-intencionados.

Talvez, por esta razão, o presidenciável tenha fugido dos meios tradicionais, objetivando operar livremente com a ajuda da proliferação digital de Fake news a fim de ganhar o pleito eleitoral a todo custo, angariando votos por meio da (des)informação e da imperícia dos usuários em checar as fontes fidedignas das informações que foram manuseadas de forma indevida, antiética e leviana.

\section{FAKE NEWS: WHAT ARE AND HOW INTER(ACT) IN THE ERA OF POST-TRUTH}

ABSTRACT: The post-truth became something conditional in the presidential election of 2018 in Brazil, in this event a true hybrid, ideological and discursive war was fought around the political, economic and cultural power. Therefore, the information was strategically conducted in order to foster discord between the hegemonic elite holding the financial and political capital and the groups with minority political representation that despite being numerous are today the most affected By the governmental and political decisions of a conservative, ultraliberal, authoritarian and entreguista nature. Thus, in this article, I describe and analyze in the light of the analysis of critical discourse the

\footnotetext{
11 Midiativismo, que corresponde a junção de midia + ativismo (media + activism), na perspectiva progressitas, enfocada neste texto, desenvolve-se, modifica-se e amplia-se com o advento das tecnologias de informação e comunicação, na era da Internet (PERUZZO, 2018, p. 54).
} 
multimodal and ideological constitution of the political discourse of the conservative right, reactionary and Brazilian elitist in favor of the presidential campaign of Jair Messias Bolsonaro, Materialized in the reproduction of some Fake news shared on the pages Brasil Verde e Amarelo e Brasil, teu povo acordou. The critical multimodal analysis evidenced that the objective of the Fake news, replicated on Facebook, were (dis) informing and manipulating the voters, followers, finally, the population who had access to these discourses marked by the post-truth about the Possible danger of the return of a left-wing government capable of subverting the patriotic, conservative, ultraliberal and Christian values of the Brazilian family.

KEYWORDS: Fake news; Political Discourse; Discursive Materiality; Multimodality.

\section{REFERÊNCIAS}

ARAÚJO, Júlio; LEFFA, Vilson. (orgs.). Redes sociais e ensino de línguas: o que temos de aprender?. 1. ed. São Paulo: Parábola Editorial, 2016.

CARVALHO, Mariana Freitas Canielo de.; MATEUS, Cristielle Andrade. Fake news e desinformação no meio digital: análise da produção científica sobre o tema na área de ciência da informação. Múltiplos olhares em Ciência da Informação. Número Especial EREBD, p. 1-16, 2018. Disponível em: http://portaldeperiodicos.eci.ufmg.br/index.php/moci/article/view/3760. Acesso em: 21 abr. 2019.

CHOULIARAKI, Lilie.; FAIRCLOUGH, Norman. Critical discourse analysis in organizational studies: towards an integrationist methodology. Journal of Management Studies, v. 47, n. 6, p. 1213-1218, 2010.

FAIRCLOUGH, Norman. Analysing Discourse: textual analysis for social research. London: Routledge, 2003.

FAIRCLOUGH, Norman. Discurso e mudança social. Trad. Izabel Magalhães. Brasília: Editora Universidade de Brasília, 2001.

FRIAS FILHO, Otavio. O que é falso sobre Fake news. Revista USP, n. 116, p. 39-44, (2018): Dossiê Pós-Verdade e Jornalismo. Disponível em: http://www.revistas.usp.br/revusp/article/view/146576/140222. Acesso em: 23 abr. 2019.

GOMES, Pedro Gilberto. Midiatização: um conceito, múltiplas vozes. In: A. FAUSTO NETO; N.R. ANSELMINO; I.L. GINDIN (orgs.), Relatos de investigaciones sobre mediatizaciones. Rosario, Editorial de la Universidad Nacional de Rosario, 2015, p. 33-54.

GOMES, Pedro Gilberto. Midiatização: um conceito, múltiplas vozes. Revista Famecos mídia, cultura e tecnologia. Porto Alegre, v. 23, n. 2, mai., p. 1-20, 2016. Disponível em: http://revistaseletronicas.pucrs.br/ojs/index.php/revistafamecos/article/view/22253. Acesso em: 21 abr. 2019. 
GEE, James Paul. A Situated Sociocultural Approach to Literacy and Technology, 2009. Available at: <http://www.jamespaulgee.com/node/6>. Acesso em: 20 abr. 2019.

HAJVARD, Stig. Midiatização: conceituando a mudança social e cultural. Matriz̧es, 8(1):21-44, 2014. Disponível em: https://www.periodicos. usp.br/matrizes/article/view/82929. Acesso em: 21 abr. 2019.

HARVEY, David. Condição pós-moderna. Uma pesquisa sobre as origens da mudança cultural. São Paulo: Edições Loyola, 2012.

PEIXOTO, Maria Eduarda Gonçalves. O escândalo político como luta social: uma análise de discurso crítica do evento midiático Novos aloprados. 2014. 213f. Dissertação (Mestrado em Linguística Aplicada) - Universidade Estadual do Ceará, Centro de Humanidades, Programa de Pós-Graduação em Linguística Aplicada, Fortaleza, 2014.

PERUZZO, Cicilia M. Krohling. Cidadania comunicacional e tecnopolítica: feições do midiativismo no âmbito dos movimentos sociais populares. In: BRAIGHI, Antônio Augusto; LESSA, Cláudio; CÂMARA, Marco Túlio (orgs.). Interfaces do Midiativismo: do conceito à prática. CEFET-MG: Belo Horizonte, 2018. p. 43-61. Disponível em: https://interfacesdomidiativismo.files.wordpress.com/2018/06/e-book-interfaces-do-midiativismo1.pdf.

Acesso em: 28 abr. 2019.

MELO, Iran Ferreira de. Análise Crítica do Discurso: modelo de análise linguística e intervenção social. ESTUDOS LINGUÍSTICOS, São Paulo, 40 (3): p. 1335-1346, set-dez. 2011. Disponível em: https://revistas.gel.org.br/estudos-linguisticos/article/view/1257. Acesso em: 10 abr. 2019.

RAMALHO, Raul.; MAIA, Kênia. Estudos metodológicos: a aplicação da Análise de Discurso para interpretar a produção de sentido de coletivos midiativistas. Verso e Reverso Revista de Comunicação, 32(81):187-200, set./dez. 2018. Disponível em: http://revistas.unisinos.br/index.php/versoereverso/article/view/ver.2018.32.81.02. Acesso em: 23 abr. 2019.

RECUERO, Raquel. Introdução à análise de redes sociais. Salvador: EDUFBA, 2017. Disponível em: https://repositorio.ufba.br/ri/bitstream/ri/24759/3/AnaliseDeRedes.epub. Acesso em: 21 abr. 2019.

RECUERO, Raquel. Discurso mediado por computador nas redes sociais. In: ARAÚJO, Júlio; LEFFA, Vilson. (orgs.). Redes sociais e ensino de linguas: o que temos de aprender?. 1. ed. São Paulo: Parábola Editorial, 2016. p. 17-32.

SODRÉ, Muniz. Antropológica do espelho: uma teoria da comunicação linear em rede. 8. ed, Petrópolis, Vozes, 2013. 272 p.

TEIXEIRA, Vitoria Matheus.; MARCOS, Amanda Duarte.; MACHADO, Maria Luísa Horácio Gomes.; CABRAL, Hildeliza Lacerda Tinoco Boechat. As fakes news e suas consequências nocivas à sociedade. Anais do Encontro Virtual de Documentação em Software Livre e Congresso Internacional de Linguagem e Tecnologia Online. 2018. p.1-6. Disponível em: 
http://www.periodicos.letras.ufmg.br/index.php/anais linguagem tecnologia/article/view/15058/1125612218. Acesso em: 21 abr. 2019.

THOMPSON, John B. Ideologia e cultura moderna: teoria social crítica na era dos meios de comunicação de massa. 3. ed. Petrópolis: Editora Vozes, 2011.

TOMAZI, Micheline Mattedi.; EFFGEN, Zirlene.; SESSA, Ariel. A força das relações de poder no discurso político de um Projeto de lei: ideologia de exclusão do nome social. Revista (Com)textos Linguísticos, v. 11, n. 20 (2017), pp. 125-146, 2017. Disponível em:

http://periodicos.ufes.br/contextoslinguisticos/article/view/18168/12569. Acesso em: 23 abr. 2019.

VAN DIJK, Teun A. Discurso e Poder. São Paulo: Contexto, 2010.

VAN DIJK, Teun A. Discurso e contexto: uma abordagem sociocognitiva. (Trad. Rodolfo Ilari). São Paulo: Contexto, 2012.

VAN DIJK, Teun A. Análise Crítica do Discurso. In: TOMAZI, Micheline Mattedi.; ROCHA, Lúcia Helena Peyroton da. POMPEU, J. C. (orgs.). Estudos discursivos em diferentes perspectivas: mídia, sociedade e direito. São Paulo: Terracota, 2016, p. 19-42.

WODAK, Ruth. Do que trata a ACD: um resumo de sua história, conceitos importantes e seus desenvolvimentos. Linguagem em (Dis)curso, v. 4, n. esp., p. 223-243, 2004. Disponível em: http://www.portaldeperiodicos.unisul.br/index.php/Linguagem_Discurso/article/view /297/313. Acesso em: 20 abr. 2019.

Recebido em: 20/05/2019.

Aprovado em: 30/05/2019. 